\title{
Bending Performance of Steel/CFRP Plate-Reinforced Core Timber Beams
}

\author{
X. Y. Xiong, ${ }^{a, 1}$ Y. Q. Z. Wang, ${ }^{a}$ X. X. Lu, ${ }^{a}$ and R. J. Xue ${ }^{b}$ \\ ${ }^{a}$ Tongji University, College of Civil Engineering, Shanghai, China \\ ${ }^{\mathrm{b}}$ Shanghai Nuclear Engineering Research \& Design Institute, Shanghai, China \\ ${ }^{1}$ Xiong_xueyu@tongji.edu.cn
}

Experimental study and theoretical analysis on flexural behaviour of four core timber beams (one is unreinforced, three are reinforced with steel/CFRP plate) have been conducted. The experimental results show that the bearing capacity of core timber beams reinforced with steel/CFRP (carbon fiber reinforced plastics) plate can be increased by 67.5 97.1\% and exhibit higher stffness, as compared with the unreinforced ones. On this basis, three kinds of failure modes of core timber beams reinforced with steel/CFRP plate are discussed, namely: wood fiber tensile failure, wood fiber compression failure and carbon fiber plate tensile failure. For different failure modes, the compression steel plate yield is cons idered to derive the formula for calculating the bending capacity of core timber beams reinforced with steel/ CFRP plate. The values calculated by the proposed formula are in good agreement with the experimental results, and, thus, can be applied to the engineering practice.

Keywords: bending performance, steel, CFRP, reinforcement, core timber beams.

Introduction. The traditional timber structure has an important position in the history of Chinese architecture. However, because of the effect of weathering and long time span, the most timber structures are seriously damaged. Wherein, due to disrepair, there will be leakage of raindrops, leading to the beam members decayed from the top to the core of the beam. The wood decay reduces the effective cross section of the beam, greatly weakening its bearing capacity. Unless reinforced in time, ancient timber buildings become unreliable and hazardous.

In order to preserve the original style of ancient timber buildings as much as possible, the core replacement method can be used to repair the decayed beams by replacing the decayed part of the beams with a new high-strength core timber beams, which will bear the most of the load. This not only removes the decayed part of wood beams and prevents further damage, but also saves the original feature of carving and painting. But the core timber beams need to be reinforced because of the smaller cross-sectional area.

There are three methods using carbon fiber reinforced plastic (CFRP) material to reinforce wood beams, namely: CFRP sheet, CFRP bar and CFRP plate. Using CFRP plate to reinforce wood beams will significantly improve the bearing capacity because of the larger cross-sectional area, so it is suitable for reinforcement of core beam. Dagher et al. [1] tested nine Glulam beams reinforced by FRP (fiber reinforced plastic) plate and 3 original beams. The results show that when FRP reinforcement ratio is in the range of $1-3 \%$, the bearing capacity of timber beams can be increased by $56 \%$ and stiffness can be increased by $37 \%$. The failure of reinforced timber beams occurred due to wood fiber compression failure. Dagher reported that the above increase is due to better utilization of the compressive strength of wood. Hernandez et al. [2] conducted the experimental research on 12 timber beams reinforced with GFRP (glass fiber reinforced plastic) plate to verify the feasibility of the reinforcement method. The volume rate of GFRP is $3 \%$, the stiffness of Glulam beams can be increased by $18 \%$, the bearing capacity increased by $26 \%$. Hernandez et al. [2] also pointed out that reinforcement of the tensile side is more effective, as the reinforcing equivalent of GFRP plate at top and bottom side of the beam. Issa and Kmeid 
[3] reported that the use of steel or CFRP reinforcement has changed the mode of failure from brittle to ductile and has increased the bearing capacity of the beams, which reduced the need of a top grade laminate on the extreme tension face and provided lower product variability. Raftery and Harte [4] used FRP plate to reinforce glulam beams and achieved moderate enhancement of stiffness, while more significant improvement in the ultimate moment capacity was obtained. They also pointed out that improved utilization of the compression strength of the timber is obtained when FRP reinforcement is included. Li and $\mathrm{Xu}$ [5] performed a series of tests, in which timber beams were reinforced with steel or CFRP plates. It was shown that the flat section hypothesis is still valid, and timber beam reinforcement with steel plate or CFRP plate was a very promising reinforcement technique $[5,6]$. Jasienko and Novak [7] conducted an experimental program to study timber beams reinforced with steel plates, and showed that the bearing capacity of the reinforced specimens increased by as much as $100 \%$ relative to that of unreinforced reference specimens.

Current research on timber beams reinforced with plates mostly focus on plates glued to the tensile side, in order to improve the bearing capacity of reinforced timber beams. In this study, in order to make the bearing capacity of core timber beams equal to that of the original timber beams, the method of reinforcing the beam with plate at the bottom and top sides is used. CFRP material has excellent tensile properties, but its compressive performance is poor. In order to improve the ductility, CFRP plates are glued to the bottom and steel plates at the top of the timber beams.

\section{Experimental.}

1.1. Test Detail. ZXL-1 is a control beam, and the rest were reinforced with CFRP and steel plates to investigate its effects on bearing capacity, stiffness and ductility. The beam specimens tested varied in strengthening amount, as shown in Table 1, and specimen dimensions are shown in Fig. 1.

$\mathrm{T}$ a $\mathrm{b} 1$ e 1

Reinforcement Program of Specimens

\begin{tabular}{|c|c|c|c|}
\hline $\begin{array}{c}\text { Specimen } \\
\text { No. }\end{array}$ & $\begin{array}{c}\text { Specimen dimensions } \\
\text { (length } \times \text { width } \times \text { height, mm) }\end{array}$ & $\begin{array}{c}\text { Strengthening } \\
\text { scheme }\end{array}$ & $\begin{array}{c}\text { Plate thickness } \\
\text { top/bottom }(\mathrm{mm})\end{array}$ \\
\hline ZXL-1 & $2165 \times 80 \times 150$ & Control beam & - \\
\hline ZXL-2 & $2165 \times 80 \times 150$ & $\begin{array}{c}\text { Galvanized steel } \\
\text { plate/CFRP plate }\end{array}$ & $1.0 / 1.4$ \\
\hline ZXL-3 & $2165 \times 80 \times 150$ & $\begin{array}{c}\text { Galvanized steel } \\
\text { plate/CFRP plate }\end{array}$ & $1.5 / 1.4$ \\
\hline ZXL-4 & $\begin{array}{c}\text { Galvanized steel } \\
\text { plate/CFRP plate }\end{array}$ & $2.0 / 1.4$ \\
\hline
\end{tabular}

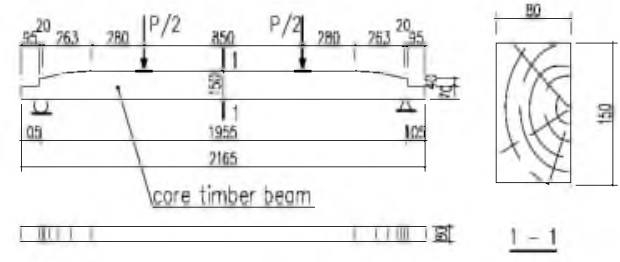

a

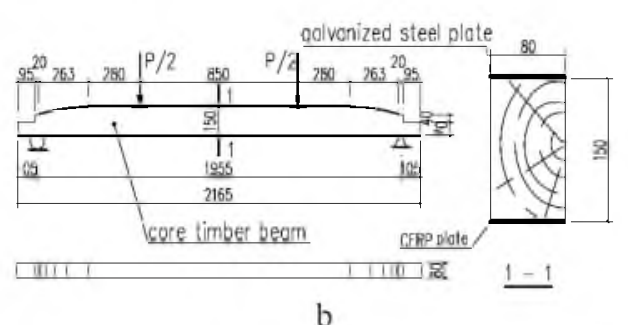

b

Fig. 1. Geometry of test specimens: (a) ZXL-1; (b) ZXL-2-ZXL-4. 
The positions of CFRP hoops pasted to the core beams are shown in Fig. 2, which ensured the bonding reliability between wood and plate. All specimens are tested in four points bending, as shown in Fig. 3. The test was carried out by using the two-point bending loading scheme. The range of the jack is $200 \mathrm{kN}$, and each level of load is $5 \mathrm{kN}$. The loading duration is about $1 \mathrm{~min}$. When the specimen was close to failure, the loading would slow down continuously until the specimen failed. In order to prevent a lateral instability and failure in the loading process, two supports were added at both sides of the specimen. A certain distance was maintained between the supports and specimen to eliminate the influence of vertical load impact.

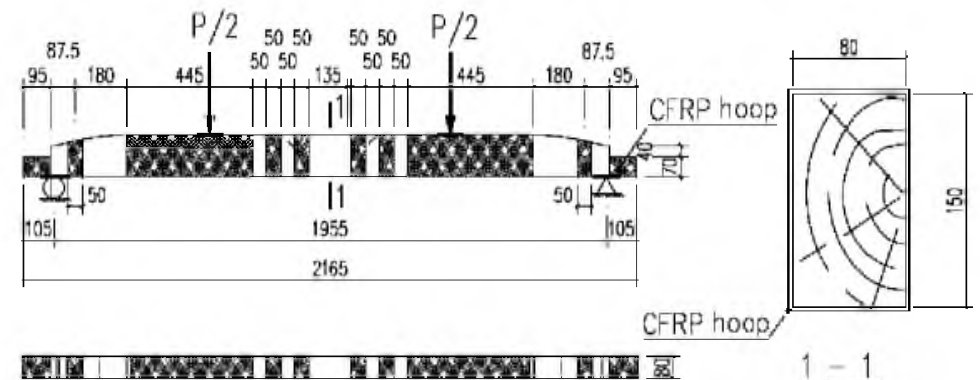

Fig. 2. CFRP hoops arrangement of ZXL-2-ZXL-4.

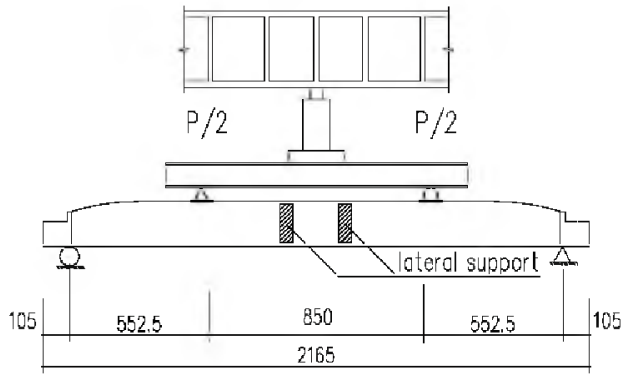

Fig. 3. Loading program.

In this experiment, Chinese fir was chosen as the model material. Its compressive strength is $24.66 \mathrm{MPa}$, tensile strength is $60.2 \mathrm{MPa}$, elastic modulus is $7956 \mathrm{MPa}$. This experiment adopted high-strength CFRP plate with tensile strength of $2594.3 \mathrm{MPa}$, elastic modulus is $16 \cdot 10^{5} \mathrm{MPa}$. The galvanized steel plates yield strength is $352.8 \mathrm{MPa}$, elastic modulus is $185 \cdot 10^{5} \mathrm{MPa}$. The tensile shear strength of structural adhesive between plate and wood is $18.0 \mathrm{MPa}$, and the tensile shear strength of epoxy resin adhesive between CFRP plate and wood is $16.7 \mathrm{MPa}$ The material properties of wood and steel were obtained from the test. The mechanical properties of CFRP plate, structural adhesive and epoxy resin were tested by the National Chemical Building Materials Testing Center, which was commissioned by supplier Shanghai Building Technology Co., Ltd.

1.2. Beam Failure Case. The control beam failed at the mid span, while the compression steel plate of the composite reinforced specimen ZXL-2, reversed due to buckling during loading procedure with the compressive wood wrinkle. Finally, the beam failed due to appearance of several vertical cracks. Similarly, specimen ZXL-3 also displayed the reverse of the steel plate due to buckling. However, because of the knag near the right loading point, specimen failure occured in advance. Specimen ZXL-4 had a big longitudinal crack before test, so the beam split into 2 layers before the final fracture. Failure phenomena of each specimen are shown in Fig. 4. 

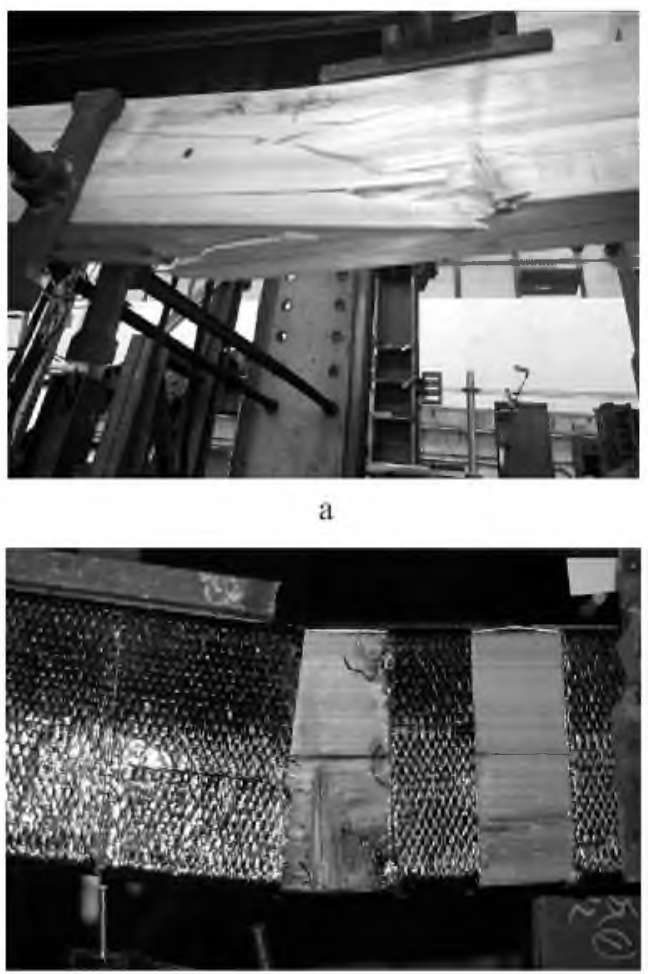

$\mathrm{c}$

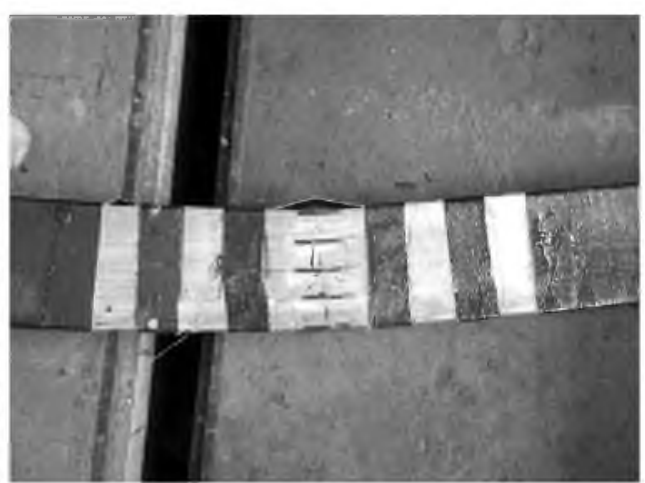

b

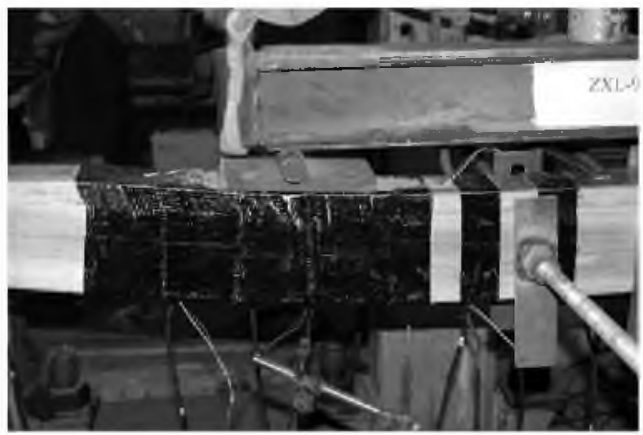

d

Fig. 4. Failure modes: (a) ZXL-1; (b) ZXL-2; (c) ZXL-3; (d) ZXL-4.

1.3. Experimental Results. The changes of bearing capacity are listed in Table 2. As compared to the control beam, composite reinforcement can improve the ultimate bearing capacity from 67.5 to $97.1 \%$, the deflections of all reinforced specimens are also increased.

$\mathrm{T}$ a b 1 e 2

Bearing Capacity and Deflection of Specimens

\begin{tabular}{|c|c|c|c|c|}
\hline $\begin{array}{c}\text { Specimen } \\
\text { No. }\end{array}$ & $\begin{array}{c}\text { Plate thickness } \\
\text { top/bottom }(\mathrm{mm})\end{array}$ & $\begin{array}{c}\text { Bearing capacity } \\
(\mathrm{kN})\end{array}$ & $\begin{array}{c}\text { Deflection } \\
(\mathrm{mm})\end{array}$ & $\begin{array}{c}\text { Increase amplitude } \\
\text { of bearing capacity } \\
(\%)\end{array}$ \\
\hline ZXL-1 & - & 43.37 & 29.04 & - \\
\hline ZXL-2 & $1.0 / 1.4$ & 85.48 & 46.82 & 97.1 \\
\hline ZXL-3 & $1.5 / 1.4$ & 76.97 & 49.43 & 77.5 \\
\hline ZXL-4 & $2.0 / 1.4$ & 72.66 & 62.45 & 67.5 \\
\hline
\end{tabular}

The load-deflection curves are shown in Fig. 5, which implies that the bearing capacity and stiffness of the core timber beams composite reinforced by steel and CFRP plate are significantly improved. There is a knag in the tensile zone of ZXL-3 and original longitudinal cracks in ZXL-4, so although the reinforcement levels of these specimens were slightly higher than that of ZXL-2, the respective bearing capacity and stiffness values are lower than those of ZXL-2. The failures of all composite reinforced specimens began with wood fiber fracture, which led to strongly manifested brittle failure. 


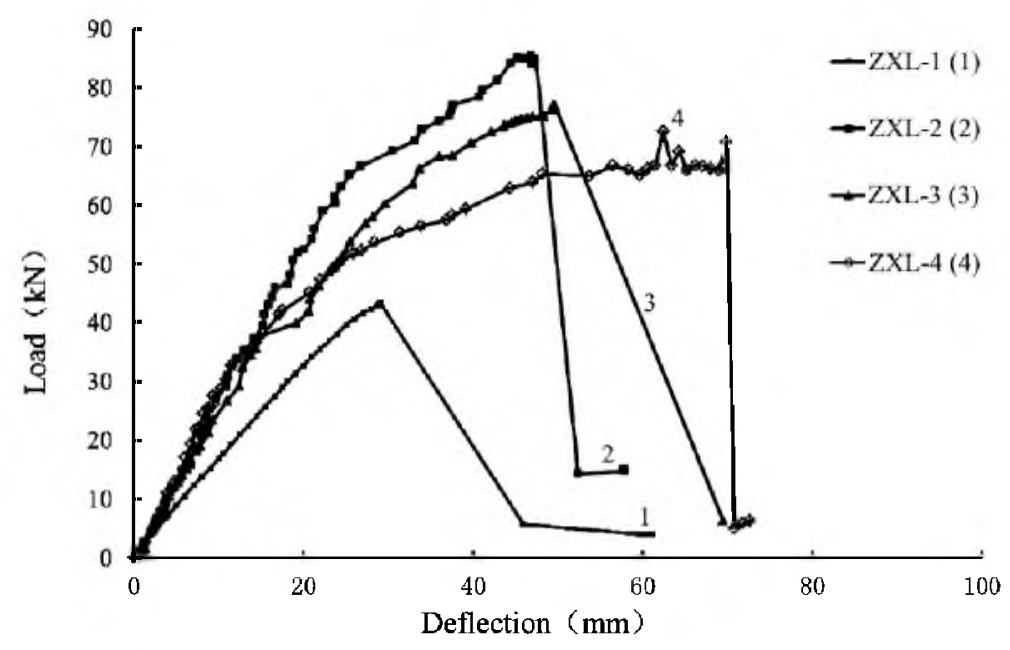

Fig. 5. Load versus midspan deflection curves of test beams.

\section{Theoretical Analysis.}

2.1. Bending Failure Modes. Due to the difference in compressive and tensile strength values of timber, the axial tensile test of the timber showed the brittle failure, while axial compressive test of the timber is ductile failure, which means there will be large plastic deformation after the timber reached the ultimate compressive strength. Under the condition that wooden beams meet the flat section hypothesis, the tensile or compressive edge fibers of the unreinforced beams cross section may be the first to reach the ultimate tensile or compressive strain, respectively. At the same time, the elastic modulus and tensile strength of carbon fiber material are much higher than those of timber, so under the same strain, low strength of the CFRP plate breaking may precede the wood fiber breaking. Based on the above analysis, the bending failure modes of wooden beams can be divided into the following 3 types:

(1) The bending failure is caused by tensile timber fiber abruption. Due to the large compression plasticity of timber, this failure is the most common mode. The tensile failure of the timber fiber can be further subdivided into the following 2 conditions according whether the steel plate was yield then:

(i) when the tensile failure of the wood fiber occurs, the compression steel plate does not yield;

(ii) when the tensile failure of the wood fiber occurs, the compression steel plate yield.

(2) The bending failure is caused by the edge timber fiber of compression zone crushed, uplift or splitting, which similar to ordinary reinforced concrete over reinforced beam, occurring mainly in the unreinforced wood beams of which compressive strength relative tensile strength is too low and the reinforced wood beams of which tensile reinforcement material is excessively used relatively:

(i) when the compression failure of the wood fiber occurs, the compression steel plate does not yield;

(ii) when the compression failure of the wood fiber occurs, the compression steel plate yields.

(3) The bending failure is caused by CFRP abruption. This mode of failure usually occurs in the reinforced beams of which strength of CFRP is relatively low and wood tensile strength and compressive strength are high. Due to the high strength of CFRP material, the compression steel plate generally yields at the CFRP abruption. 
2.2. Stress-Strain Relationship of Section. Assuming the cohesion of plate and beam is reliable and the cross section saisfies the flat section hypothesis, the relationship between stress and strain of the cross section takes the form shown in Fig. 6.
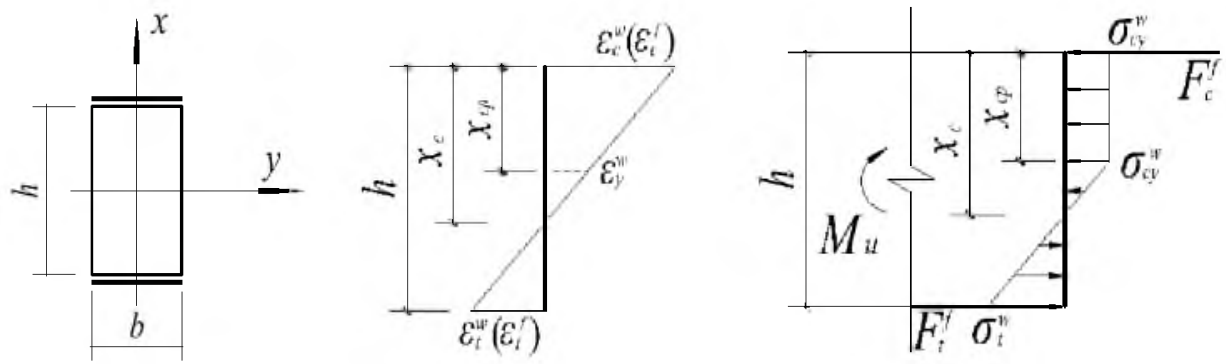

Fig 6. Stress-strain relationship of section.

2.3. Tensile Failure of Wood Fiber.

(1) Flat section hypothesis is

$$
\frac{h-x_{c}}{x_{c}-x_{c p}}=\frac{\sigma_{t}^{w}}{\sigma_{c y}^{w}}=\frac{\sigma_{t u}^{w}}{\sigma_{c y}^{w}}=R_{\sigma},
$$

where $\sigma_{c y}^{w}$ and $\sigma_{t u}^{w}$ are the yield compressive and ultimate tensile stresses of wood fiber, respectively, $h$ is the section height, $x_{c}$ is the height of compression zone of cross section, $x_{c p}$ is the plastic zone development height of compression zone of cross section, and $R_{O}$ is the ratio of the maximum tensile and compressive stresses of the wood fiber.

(2) Static equilibrium condition of section is as follows

$$
\begin{gathered}
\sum F_{i}=\int_{-h / 2}^{h / 2} \sigma^{w}(x) b(x) d x+\sigma_{t}^{f} A_{t}^{f}+\sigma_{c}^{f} A_{c}^{f}=0, \\
b\left[\sigma_{c y}^{w} x_{c p}+\frac{1}{2} \sigma_{c y}^{w}\left(x_{c}-x_{c p}\right)-\frac{1}{2} \sigma_{t u}^{w}\left(h-x_{c}\right)\right]+\sigma_{c}^{f} A_{c}^{f}-\sigma_{t}^{f} A_{t}^{f}=0,
\end{gathered}
$$

where $\sigma_{t}^{f}$ is the tensile stress of tensile reinforcement material, $A_{t}^{f}$ is the area of tensile reinforcement material, $\sigma_{c}^{f}$ is the compressive stress of compressive reinforcement materials, and $A_{c}^{f}$ is the area of compression reinforcement material.

Case 1a: When the tensile failure of the wood fiber occurs, the compression steel plate does not yield

$$
\begin{gathered}
\sigma_{c}^{f}=\frac{x_{c}}{h-x_{c}} \alpha_{E c} \sigma_{t u}^{w}, \\
\sigma_{t}^{f}=\alpha_{E t} \sigma_{t u}^{w}, \\
x_{c}+x_{c p}=R_{\sigma}\left(h-x_{c}\right)+\frac{2\left(\sigma_{t}^{f} A_{t}^{f}-\sigma_{c}^{f} A_{c}^{f}\right)}{b \sigma_{c y}^{w}},
\end{gathered}
$$


where $\alpha_{E c}$ is the ratio of the elastic modulus of the reinforcement material on the top of the beam to the elastic modulus of timber, $\alpha_{E c}=E_{c}^{f} / E^{w}$, and $\alpha_{E t}$ is the ratio of the elastic modulus of the reinforcement material on the bottom of the beam to the elastic modulus of timber, $a_{E t}=E_{t}^{f} / E^{w}$.

Simultaneously solving Eqs. (1), (4)-(6), we obtain:

$$
\begin{gathered}
x_{c p}=\frac{R_{\sigma}\left(\alpha_{E c} A_{c}^{f}+\alpha_{E t} A_{t}^{f}+b h\right)}{\left(R_{\sigma}+1\right) b}- \\
-\frac{\sqrt{\left(R_{\sigma} \alpha_{E c} A_{c}^{f}\right)^{2}+\left(b h-R_{\sigma} \alpha_{E t} A_{t}^{f}\right)^{2}+2\left(\alpha_{E c} A_{c}^{f}\right)\left(\alpha_{E t} A_{t}^{f} R_{\sigma}^{2}+\left(1+R_{\sigma}+R_{\sigma}^{2}\right) b h\right)}}{\left(R_{\sigma}+1\right) b}, \\
x_{c}=\frac{h+R_{\sigma} x_{c p}}{\left(R_{\sigma}+1\right)} .
\end{gathered}
$$

Case $1 b$ : When the tensile failure of the wood fiber occurs, the compression steel plate yields:

According to Eq. (3) the static equilibrium conditions of the section, substitute $\sigma_{c}^{f}=\sigma_{c u}^{f}$ into:

$$
b \sigma_{c y}^{w}\left(x_{c}+x_{c p}\right)=b \sigma_{t u}^{w}\left(h-x_{c}\right)+2\left(\sigma_{t}^{f} A_{t}^{f}-\sigma_{c u}^{f} A_{c}^{f}\right) .
$$

Simultaneous solving Eqs. (1), (5), and (9), we get:

$$
x_{c p}=\frac{\sigma_{c y}^{w}\left[b h\left(R_{\sigma}-1\right)+2 \alpha_{E t} R_{\sigma} A_{t}^{f}\right]-2 A_{c}^{f} \sigma_{c u}^{f}}{\left(1+R_{\sigma}\right) \sigma_{c y}^{w} b} .
$$

The calculation method of $x_{c}$ is described by Eq. (8).

(3) Calculate the moment about the neutral axis to get the ultimate bearing capacity.

$$
M=b\left[\frac{\sigma_{c y}^{w}\left(2 x_{c}^{2}+2 x_{c} x_{c p}-x_{c p}^{2}\right)^{2}}{6}+\frac{\sigma_{t}^{w}\left(h-x_{c}\right)^{2}}{3}\right]+\sigma_{t}^{f} A_{t}^{f}\left(h-x_{c}\right)+\sigma_{c}^{f} A_{c}^{f} x_{c} .
$$

\subsection{Compression Failure of Wood Fiber.}

(1) Flat section hypothesis is

$$
\frac{x_{c p}}{x_{c}-x_{c p}}=\frac{\varepsilon_{c}^{w}-\varepsilon_{c y}^{w}}{\varepsilon_{c y}^{w}}=\frac{\varepsilon_{c u}^{w}-\varepsilon_{c y}^{w}}{\varepsilon_{c y}^{w}}=\gamma_{\varepsilon}
$$

where $\varepsilon_{c y}^{w}, \varepsilon_{c u}^{w}$, and $\varepsilon_{t u}^{w}$ are the yield compressive, ultimate compressive, and ultimate tensile strains of wood fiber, respectively, $\varepsilon_{c}^{W}$ and $\varepsilon_{t}^{W}$ are the strains at the edge of the tension and compression zones of the member, respectively, $\gamma_{\varepsilon}$ is the ratio of ultimate plastic strain and elastic strain of wood fiber compression. 
(2) Section static equilibrium condition, according to Eq. (2):

$$
b\left[\sigma_{c y}^{w} x_{c p}+\frac{1}{2} \sigma_{c y}^{w}\left(x_{c}-x_{c p}\right)-\frac{1}{2} \sigma_{t}^{w}\left(h-x_{c}\right)\right]+\sigma_{c}^{f} A_{c}^{f}-\sigma_{t}^{f} A_{t}^{f}=0 .
$$

Case 2a: When the compression failure of the wood fiber occurs, the compression steel plate does not yield:

$$
\begin{gathered}
\sigma_{c}^{f}=\left(1+\gamma_{\varepsilon}\right) \alpha_{E c} \sigma_{c y}^{w}, \\
\sigma_{t}^{f}=\alpha_{E t} \sigma_{t}^{w}=\frac{h-x_{c}}{x_{c}-x_{c p}} \alpha_{E t} \sigma_{c y}^{w}, \\
b \sigma_{c y}^{w}\left(x_{c}+x_{c p}\right)=b \sigma_{t}^{w}\left(h-x_{c}\right)+2\left(\sigma_{t}^{f} A_{t}^{f}-\sigma_{c}^{f} A_{c}^{f}\right) .
\end{gathered}
$$

Simultaneously solving Eqs. (12), (14)-(16), we get:

$$
\begin{gathered}
x_{c p}=\frac{\left(1+\gamma_{\varepsilon}\right)\left(\alpha_{E c} A_{c}^{f}+\alpha_{E t} A_{t}^{f}+b h\right)}{\gamma_{\varepsilon} b}- \\
-\frac{\sqrt{\left(1+\gamma_{\varepsilon}\right)^{2}\left(\alpha_{E c} A_{c}^{f}+\alpha_{E t} A_{t}^{f}+b h\right)^{2}-\gamma_{\varepsilon}^{2} b h\left(2 \alpha_{E t} A_{t}^{f}+b h\right)}}{\gamma_{\varepsilon} b}, \\
x_{c}=\frac{1+\gamma_{\varepsilon}}{\gamma_{\varepsilon}} x_{c p} .
\end{gathered}
$$

Case 2b: When the compression failure of the wood fiber occurs, the compression steel plate yields: into:

According to Eq. (13), the static equilibrium conditions of the section, substitute

$$
b \sigma_{c y}^{w}\left(x_{c}+x_{c p}\right)=b \sigma_{t}^{w}\left(h-x_{c}\right)+2\left(\sigma_{t}^{f} A_{t}^{f}-\sigma_{c u}^{f} A_{c}^{f}\right) .
$$

Simultaneous solving of Eqs. (9), (12), and (19) yields:

$$
\begin{gathered}
x_{c p}=\frac{\sigma_{c u}^{f} A_{c}^{f}+\left(1+\gamma_{\varepsilon}\right) \sigma_{c y}^{w}\left(\alpha_{E t} A_{t}^{f}+b h\right)}{\gamma_{\varepsilon} \sigma_{c y}^{w} b}- \\
-\frac{\sqrt{\left[\sigma_{c u}^{f} A_{c}^{f}+\left(1+\gamma_{\varepsilon}\right) \sigma_{c y}^{w}\left(\alpha_{E t} A_{t}^{f}+b h\right)\right]^{2}-\gamma_{\varepsilon}^{2} \sigma_{c y}^{w 2}\left(2 \alpha_{E t} A_{t}^{f}+b h\right) b h}}{\gamma_{\varepsilon} \sigma_{c y}^{w} b} .
\end{gathered}
$$

The calculation method of $x_{c}$ is described by Eq. (18)

(3) Calculate the moment about the neutral axis to get the ultimate bearing capacity, using the equation similar to Eq. (11). 


\subsection{Tensile Failure of CFRP Plate.}

(1) Flat section hypothesis is

$$
\frac{h_{0}-x_{c}}{x_{c}-x_{c p}}=\frac{\varepsilon^{f}}{\varepsilon_{c y}^{w}}=\frac{\varepsilon_{t u}^{f}}{\varepsilon_{c y}^{w}}=\frac{\sigma_{t u}^{f}}{\alpha_{E t} \sigma_{c y}^{w}},
$$

where $\varepsilon_{t}^{f}$ and $\varepsilon_{t u}^{f}$ are the tensile and ultimate tensile strains of fiber plate, respectively, $\sigma_{t u}^{f}$ is the ultimate tensile stress of fiber plate, $h_{0}$ is the distance from fiber plate to the top of the wooden beam, and $\alpha_{E}$ is the ratio of elastic modulus of fiber plate to the timber modulus, $\alpha_{E}=E^{f} / E^{w}$.

(2) For the failure caused by abruption of CFRP, when the plate reaches the ultimate strength, the static equilibrium condition of the cross section via Eq. (2) is

$$
\begin{gathered}
b\left[\sigma_{c y}^{w} x_{c p}+\frac{1}{2} \sigma_{c y}^{w}\left(x_{c}-x_{c p}\right)-\frac{1}{2} \sigma_{t}^{w}\left(h-x_{c}\right)\right]+\sigma_{c u}^{f} A_{c}^{f}-\sigma_{t u}^{f} A_{t}^{f}=0, \\
\sigma_{c y}^{w}=\frac{x_{c}}{h-x_{c}} \frac{\sigma_{t u}^{f}}{\alpha_{E t}} \\
b \sigma_{c y}^{w}\left(x_{c}+x_{c p}\right)=b \sigma_{t}^{w}\left(h-x_{c}\right)+2\left(\sigma_{t u}^{f} A_{t}^{f}-\sigma_{c u}^{f} A_{c}^{f}\right) .
\end{gathered}
$$

Simultaneous solving of Eqs. (21), (23), and (24) yields:

$$
\begin{gathered}
x_{c p}=\frac{\sigma_{t u}^{f} b h-\alpha_{E t}\left(2 \sigma_{c u}^{f} A_{c}^{f}-2 \sigma_{t u}^{f} A_{t}^{f}+\sigma_{c y}^{w} b h\right)}{\left(\alpha_{E t} \sigma_{c y}^{w}+\sigma_{t u}^{f}\right) b}, \\
x_{c}=\frac{\alpha_{E t} \sigma_{c y}^{w} h+\sigma_{t u}^{f} x_{c p}}{\alpha_{E t} \sigma_{c y}^{w}+\sigma_{t u}^{f}} .
\end{gathered}
$$

(3) Calculate the moment about the neutral axis to get the ultimate bearing capacity via the equation similar to Eq. (11).

2.6. Comparison of Theoretical Calculation and Test Results. Using the measured timber and reinforcement material mechanical performance index marks and considering the knots, holes, dry shrinkage cracks and other defects in the tension zone of timber, which may reduce the tensile strength, the value of 0.85 is used in this study in the aforementioned theoretical equations to calculate [8]. We consider the minimum load capacity of timber fiber tensile failure, timber fiber compression failure, fiber plate tensile destruction, this three kinds of failure modes, as the calculated ultimate bearing capacity of the members, which differs from the test results shown in Table 3. It is obvious that in addition to ZXL-4 occurred staggered layer disruption of low bearing capacity, bearing capacity calculated by the formula in this study are in good agreement with the test results, which has the guiding significance for the practical engineering.

Conclusions. Based on the experimental study and theoretical analysis on flexural behavior of four core timber beams (where one is unreinforced, and three are reinforced by both steel and CFRP plate), this paper discusses the influence of steel and CFRP plate 
$\mathrm{T}$ a b 1 e 3

Bearing Capacity of Core Beam Comparison between Theoretical and Experimental Values

\begin{tabular}{|c|c|c|c|c|c|}
\hline $\begin{array}{l}\text { Specimen } \\
\text { No. }\end{array}$ & $\begin{array}{c}\text { Test bearing } \\
\text { capacity } \\
(\mathrm{kN})\end{array}$ & $\begin{array}{c}\text { Calculating } \\
\text { bearing capacity } \\
(\mathrm{kN})\end{array}$ & $\begin{array}{c}\text { Test } \\
\text { failure mode }\end{array}$ & $\begin{array}{l}\text { Calculation } \\
\text { failure mode }\end{array}$ & $\begin{array}{c}\text { Relative } \\
\text { error } \\
(\%)\end{array}$ \\
\hline ZXL-1 & 43.37 & 45.50 & $\begin{array}{l}\text { Tensile failure } \\
\text { of wood fiber }\end{array}$ & $\begin{array}{l}\text { Tensile failure } \\
\text { of wood fiber }\end{array}$ & -1.39 \\
\hline ZXL-2 & 85.48 & 73.63 & $\begin{array}{c}\text { Tensile failure } \\
\text { of wood fiber after } \\
\text { yielding of steel }\end{array}$ & $\begin{array}{c}\text { Compression } \\
\text { failure of wood } \\
\text { fiber after yielding } \\
\text { of steel }\end{array}$ & -13.86 \\
\hline ZXL-3 & 76.97 & 79.93 & $\begin{array}{c}\text { Compression } \\
\text { failure of wood } \\
\text { fiber after yielding } \\
\text { of steel }\end{array}$ & $\begin{array}{c}\text { Compression } \\
\text { failure of wood } \\
\text { fiber after yielding } \\
\text { of steel }\end{array}$ & 3.85 \\
\hline ZXL-4 & 72.66 & 85.80 & $\begin{array}{l}\text { Staggered layer } \\
\text { disruption }\end{array}$ & $\begin{array}{c}\text { Compression } \\
\text { failure of wood } \\
\text { fiber after yielding } \\
\text { of steel }\end{array}$ & 18.08 \\
\hline
\end{tabular}

composite reinforcement on the bearing capacity and stiffness of wood beams. The following conclusions can be drawn:

1. The steel/CFRP plate composite reinforcement can significantly improve the bearing capacity of timber core beams. The maximal improvement of the bearing capacity can reach $97.1 \%$.

2. Due to the steel plates yielding before the failure of the test specimens, relative to the control specimen, all of the reinforced specimens have shown a certain ductility. Although specimen ZXL-2 has the highest bearing capacity, considering the fact that ZXL-3 has numerous knots in the tension area, and ZXL-4 has longitudinal cracks and other defects initially, which weakened the ultimate bearing capacity, the results obtained cannot prove trhaqt ZXL-2 reinforcement is the optimal method. From the theoretical analysis it follows that the effect of reinforcement is higher when the steel plate contribution is close to that of the CFRP plate.

3. Although the steel plate pasted in the compression zone exhibited reverse bulges at the end of the experiment, it does not lead to the bearing capacity loss and fracture, due to the hoop restriction of the CFRP. This indicates that the arrangement of CFRP cloth hoops can improve the bonding effect of plates and beams to prevent the stripping failure of reinforced timber beams.

4. This paper analyzes 3 different failure modes of steel/CFRP plate composite reinforcement of timber beams and establishes the engineering formula of flexural bearing capacity. The values calculated by the proposed formula are in good agreement with the experimental results, which proves that the formula can be applied to the engineering practice.

Acknowledgments. This work was financially supported by the 12 th five-year National Science and Technology Support Plan (2012BAJ08B00) "Huizhou Ancient Architecture's Settlement Protection and Inheritance Key Technology Research and Demonstration." 
1. H. J. Dagher, T. E. Kimball, and S. M. Shaler, "Effect of FRP reinforcement on low grade eastern hemlock glulams," in: Proc. of the National Conference on Wood Transportation Structures (October 23-25, 1996, Madison, Wisconsin), General Technical Report No. FPL-GTR-96, Forest Products Laboratory, Madison, WI (1996).

2. R. Hernandez, J. F. Davalos, S. S. Sonti, et al., Strength and Stiffness of Reinforced Yellow-Poplar Glued-Laminated Beams, Research Paper FPL-RP-554, Forest Products Laboratory, Madison, WI (1997).

3. C. A. Issa and Z. Kmeid, "Advanced wood engineering: glulam beams," Constr. Build. Mater, 19, No. 2, 99-106 (2005).

4. G. M. Raftery and A. M. Harte, "Low-grade glued laminated timber reinforced with FRP plate," Compos. Part B-Eng., 42, No. 4, 724-735 (2011).

5. X. M. Li and Q. F. Xu, "Experimental research on timber beams strengthened with CFRP plates," J. Build. Struct., 10, 123-125 (2011).

6. Q. F. Xu, L. Zhu, J. F. Chen, and X. M. Li, "An experimental study of timber beams strengthened with steel plates," J. Centr. South Univ. (Natur. Sci. Edit.), 43, No. 3, 1153-1159 (2012).

7. J. Jasienko and T. P. Nowak, "Solid timber beams strengthened with steel plates Experimental studies," Constr. Build. Mater., 63, 81-88 (2014).

8. Z. Y. Su, Destruction Causes Analysis and Reinforcement Technology Research for Huizhou Ancient Building, Tongii University, Shanghai (2014).

Received 30. 08. 2016 